\title{
Corrosion tests in liquid lithium-lead of multi-layer ceramic coatings
}

\author{
Erika Akahoshi ${ }^{a}$, Moeki Matsunaga ${ }^{a}, K_{\text {Keisuke Kimura }}{ }^{\text {, Kazuki Nakamura }}{ }^{\text {a }}$, \\ Martin Balden $^{\mathrm{b}}$, Yoshimitsu Hishinuma ${ }^{\mathrm{c}}$, Takumi Chikada ${ }^{\mathrm{a}^{*}}$ \\ ${ }^{a}$ Shizuoka University, Shizuoka, Japan \\ ${ }^{b}$ Max-Planck-Institut für Plasmaphysik, Garching, Germany \\ ${ }^{c}$ National Institute for Fusion Science, Gifu, Japan
}

\begin{abstract}
Tritium permeation through structural materials in fusion reactor blanket systems is a critical issue from the viewpoints of fuel loss and radiological safety. Ceramic coatings have been investigated to prevent tritium permeation; however, corrosion of the coatings by blanket materials, especially corrosive liquid tritium breeders such as lithium-lead is serious. In our previous study, the improvement of permeation reduction performance using an erbium oxide $\left(\mathrm{Er}_{2} \mathrm{O}_{3}\right)$-zirconium oxide $\left(\mathrm{ZrO}_{2}\right)$ two-layer coating was confirmed, but it did not show substantial corrosion resistance. In this study, various multi-layer coatings were fabricated by metal organic decomposition and then exposed to lithium-lead under static conditions to investigate precise corrosion behaviors of multi-layer coatings. After lithium-lead exposure for $1000 \mathrm{~h}$ at $600{ }^{\circ} \mathrm{C}$, the outermost $\mathrm{Er}_{2} \mathrm{O}_{3}$ layer almost disappeared, while the outermost $\mathrm{ZrO}_{2}$ layer remained, indicating that $\mathrm{ZrO}_{2}$ is more suitable as the outermost layer. However, many cracks and peelings were observed on the outermost $\mathrm{ZrO}_{2}$ layer in the cases of the samples having four coating interfaces. The optimization of layer combination and the control of adhesion between the coatings are required to reduce the degradation of multi-layer coatings.
\end{abstract}

Keywords: Lithium-lead, Corrosion, Ceramic coating, Erbium oxide, Zirconium oxide

\section{Introduction}

Tritium permeation through structural materials in fusion reactor blanket systems is a critical issue from the viewpoints of fuel loss and radiological safety. One of the promising solutions is to fabricate a ceramic coating as a tritium permeation barrier on the blanket components. In our previous studies, precise deuterium permeation behaviors in the coatings have been clarified, and high permeation reduction performance was shown in ceramic coatings prepared by various methods [1]. In particular, metal organic decomposition (MOD) is one of the practical coating methods due to its possibility to fabricate on the components with complicated geometries. Moreover, the ceramic coatings such as erbium oxide $\left(\mathrm{Er}_{2} \mathrm{O}_{3}\right)$ and zirconium oxide $\left(\mathrm{ZrO}_{2}\right)$ coatings fabricated by MOD showed high permeation reduction performance [2-4]. In liquid blanket concepts, however, corrosion of the coatings by liquid tritium breeders such as lithiumlead $(\mathrm{Li}-\mathrm{Pb})$ is an unavoidable problem. In our previous study, corrosion and peelings were confirmed after static $\mathrm{Li}-\mathrm{Pb}$ exposure tests in single-layer coatings [5]. On the other hand, two-layer coatings consisting of $\mathrm{Er}_{2} \mathrm{O}_{3}$ and $\mathrm{ZrO}_{2}$ were proposed as multi-functional coatings [6]. The two-layer coatings showed higher permeation reduction performance in comparison with the single-layer coatings, but they did not show an improvement of corrosion resistance. Although the improvement of corrosion resistance by further layering was possible, the effects of layer structure on corrosion resistance have not been clarified. In this study, multi-layer coatings with various layer structures were fabricated and then exposed to Li$\mathrm{Pb}$ under static conditions for a further understanding of corrosion behaviors of multi-layer coatings.

\section{Experimental details}

\subsection{Coating preparation}

Reduced activation ferritic/martensitic steel $\mathrm{F} 82 \mathrm{H}$ (Fe-8Cr-2W, F82H-BA07 heat) square plates with dimensions of $25 \mathrm{~mm}$ in length and $0.5 \mathrm{~mm}$ in thickness were used as substrates. The coating procedure is described in detail in Ref. [6]. First, the substrates were heat-treated in order to form a chromium oxide $\left(\mathrm{Cr}_{2} \mathrm{O}_{3}\right)$ layer on the substrate and to prevent the peeling of MOD coatings [7]. The heat treatment was carried out for 10 min at $710{ }^{\circ} \mathrm{C}$ in argon and hydrogen mixture flow with each flow rate of 50 standard cubic centimeters per minute (sccm). Thereafter, $\mathrm{Er}_{2} \mathrm{O}_{3}$ and $\mathrm{ZrO}_{2}$ coatings were fabricated by MOD. The heat-treated F82H substrates were dipped into the coating precursors (Kojundo Chemical Laboratory Co., Ltd, $\mathrm{Er}-03^{\circledR}$ for $\mathrm{Er}_{2} \mathrm{O}_{3}$ and SYM-ZR0 $4{ }^{\circledR}$ for $\mathrm{ZrO}_{2}$ ) and withdrawn at a constant speed of $1.0 \mathrm{~mm} \mathrm{~s}^{-1}$ using a dip coater.

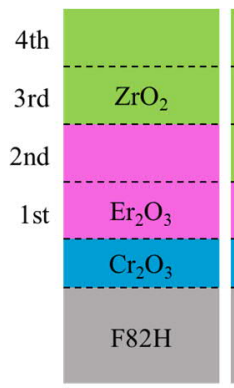

A

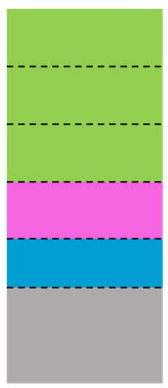

B

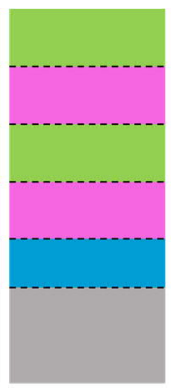

C

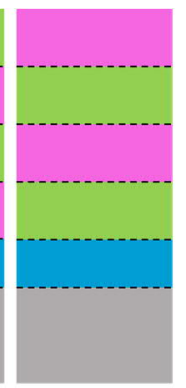

$\mathrm{D}$
Fig. 1. Layer structures of multi-layer coatings. 
After withdrawal, the samples were dried for $6 \mathrm{~min}$ at 150 ${ }^{\circ} \mathrm{C}$ and pre-heated for $2 \mathrm{~min}$ at $550{ }^{\circ} \mathrm{C}$ in air using hot plates. The process of dipping, drying, and pre-heating was repeated twice, and then the coated samples were heat-treated for $30 \mathrm{~min}$ at $700{ }^{\circ} \mathrm{C}$ in argon and hydrogen mixture flow with each flow rate of $50 \mathrm{sccm}$. The series of the process including the heat treatment was repeated four times to fabricate the multi-layer coatings. Fig. 1 summarizes layer structures of the multi-layer coatings. After a layer fabrication process, the thicknesses of the $\mathrm{Er}_{2} \mathrm{O}_{3}$ and $\mathrm{ZrO}_{2}$ layers were approximately $50 \mathrm{~nm}$ and 150 $\mathrm{nm}$, respectively. The coating thicknesses of each sample were approximately $400-500 \mathrm{~nm}$.

\subsection{Lithium-lead exposure test}

$\mathrm{Li}-\mathrm{Pb}$ exposure tests were performed under static conditions described in Ref. [8]. Li-Pb was synthesized from $99.9 \% \mathrm{Li}$ and $99.999 \% \mathrm{~Pb}$ ingots purchased from Furuuchi Chemical Co. with the atomic ratio of 15.7:84.3 under argon atmosphere in a glove box. The synthesized $\mathrm{Li}-\mathrm{Pb}$ contained impurities such as oxygen and carbon. In particular, oxygen is considered to have a significant effect on Li-Pb compatibility. In this study, $\mathrm{Li}-\mathrm{Pb}$ was synthesized and the samples were soaked into $\mathrm{Li}-\mathrm{Pb}$ under a low oxygen concentration environment $(<1$ vol\% at atmospheric pressure) as described in our previous study [5]. From the oxygen concentration of the environment in the glove box and the ingots, we assume that $\mathrm{Li}-\mathrm{Pb}$ used in this study contained 1000-10000 appm oxygen. The multi-layer coating samples cut into small specimens with the dimensions of $12 \times 12 \times 0.5 \mathrm{~mm}^{3}$ were fixed by iron wires. After setting in an iron crucible, synthesized Li-Pb of 20-25 cc was poured into the crucible in argon atmosphere. After each crucible was encapsulated in a stainless steel container, the container was set in a muffle furnace. The $\mathrm{Li}-\mathrm{Pb}$ exposure tests were conducted for $500-2000 \mathrm{~h}$ at $500-600^{\circ} \mathrm{C}$. The $\mathrm{Li}-\mathrm{Pb}$ exposure tests were conducted using one sample for each exposure temperature and duration. After exposure, the samples were picked up from liquid $\mathrm{Li}-\mathrm{Pb}$ and shook out the adhered $\mathrm{Li}-\mathrm{Pb}$ as much as possible. No cleaning process using ethanol and acetic acid was conducted in this study. Surface and cross-sectional observations of the samples were conducted by scanning electron microscopy (SEM) with energy dispersive X-ray spectroscopy (EDX) located at National Institute for Fusion Science, Japan and MaxPlanck-Institut für Plasmaphysik, Germany. Crosssectional SEM observation and EDX analysis for selected areas were conducted using a focused ion beam system. We observed the entire samples and analyze the trends. Additionally, we considered and discussed the trends in each sample based on the multiple results of the samples after the $\mathrm{Li}-\mathrm{Pb}$ exposure tests.

\section{Results}

Fig. 2 shows surface SEM images of the samples before the Li-Pb exposure test. Smooth surfaces of the coatings were confirmed in as-prepared coatings. Table 1 summarizes the outlines of the results after the $\mathrm{Li}-\mathrm{Pb}$ exposure tests. The deposition of a corrosion product was confirmed on all the sample surfaces after $\mathrm{Li}-\mathrm{Pb}$ exposure. The EDX results showed that the corrosion product mainly consisted of carbon.

Table 1. Outline of result of $\mathrm{Li}-\mathrm{Pb}$ exposure tests

\begin{tabular}{|c|c|c|c|c|c|}
\hline & $500 \mathrm{~h}, 500^{\circ} \mathrm{C}$ & $500 \mathrm{~h}, 550^{\circ} \mathrm{C}$ & $500 \mathrm{~h}, 600^{\circ} \mathrm{C}$ & $1000 \mathrm{~h}, 600^{\circ} \mathrm{C}$ & $2000 \mathrm{~h}, 600^{\circ} \mathrm{C}$ \\
\hline Sample A & No degradation & No degradation & Surface corrosion & Surface corrosion & Surface corrosion \\
\hline Sample B & $\begin{array}{l}\text { Interlamellar } \\
\text { peeling }\end{array}$ & No degradation & Surface corrosion & Surface corrosion & Surface corrosion \\
\hline Sample C & $\begin{array}{l}\text { Interlamellar } \\
\text { peelings }\end{array}$ & No degradation & $\begin{array}{c}\text { Surface corrosion } \\
\text { Peelings }\end{array}$ & $\begin{array}{c}\text { Surface corrosion } \\
\text { Cracks }\end{array}$ & $\begin{array}{c}\text { Surface } \\
\text { corrosion }\end{array}$ \\
\hline Sample D & $\begin{array}{c}\text { Surface corrosion } \\
\text { Cracks }\end{array}$ & $\begin{array}{c}\text { Surface corrosion } \\
\text { Peelings }\end{array}$ & $\begin{array}{c}\text { Surface corrosion } \\
\text { Interlamellar } \\
\text { peelings }\end{array}$ & $\begin{array}{l}\text { Loss of layer } \\
\text { Cracks }\end{array}$ & $\begin{array}{l}\text { Loss of layers } \\
\text { Peelings, Cracks }\end{array}$ \\
\hline
\end{tabular}
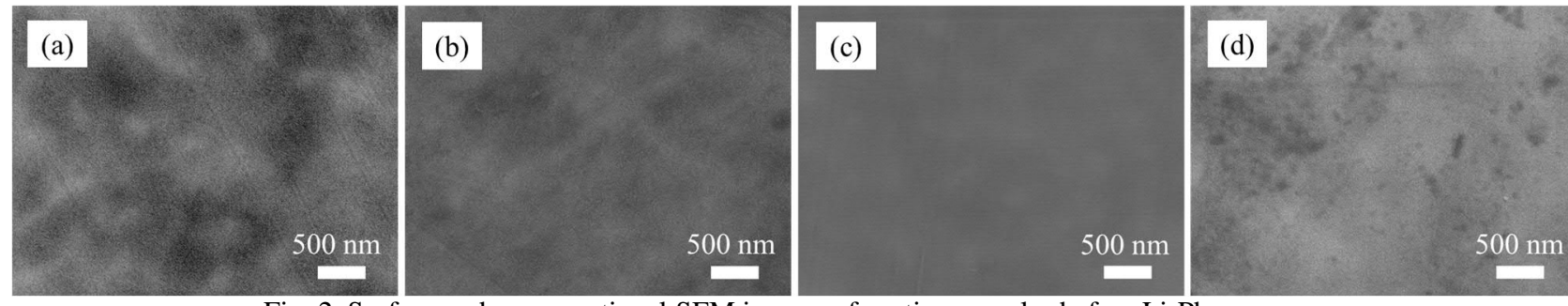

Fig. 2. Surface and cross-sectional SEM images of coating samples before Li-Pb exposure:

(a) Sample A, (b) Sample B, (c) Sample C, and (d) Sample D. 

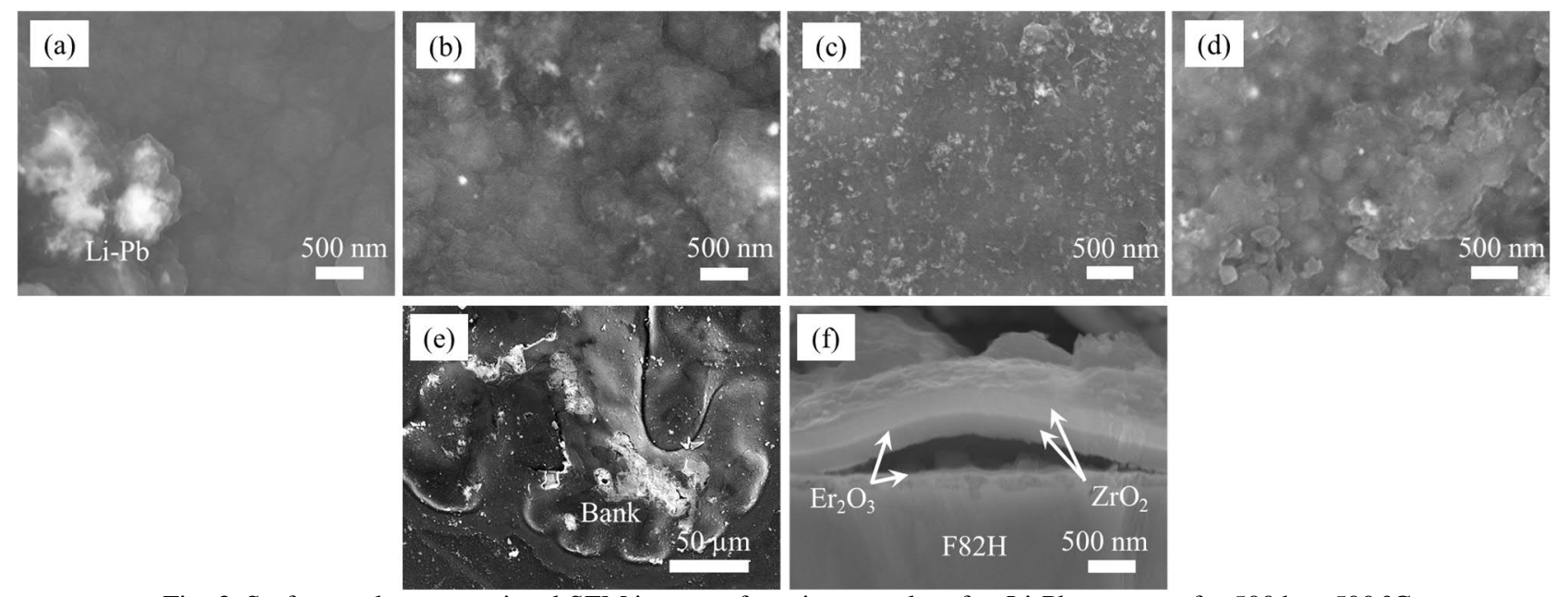

Fig. 3. Surface and cross-sectional SEM images of coating samples after $\mathrm{Li}-\mathrm{Pb}$ exposure for $500 \mathrm{~h}$ at $500{ }^{\circ} \mathrm{C}$ :

(a) Sample A, (b) (e) Sample B, (c) (f) Sample C, and (d) Sample D.
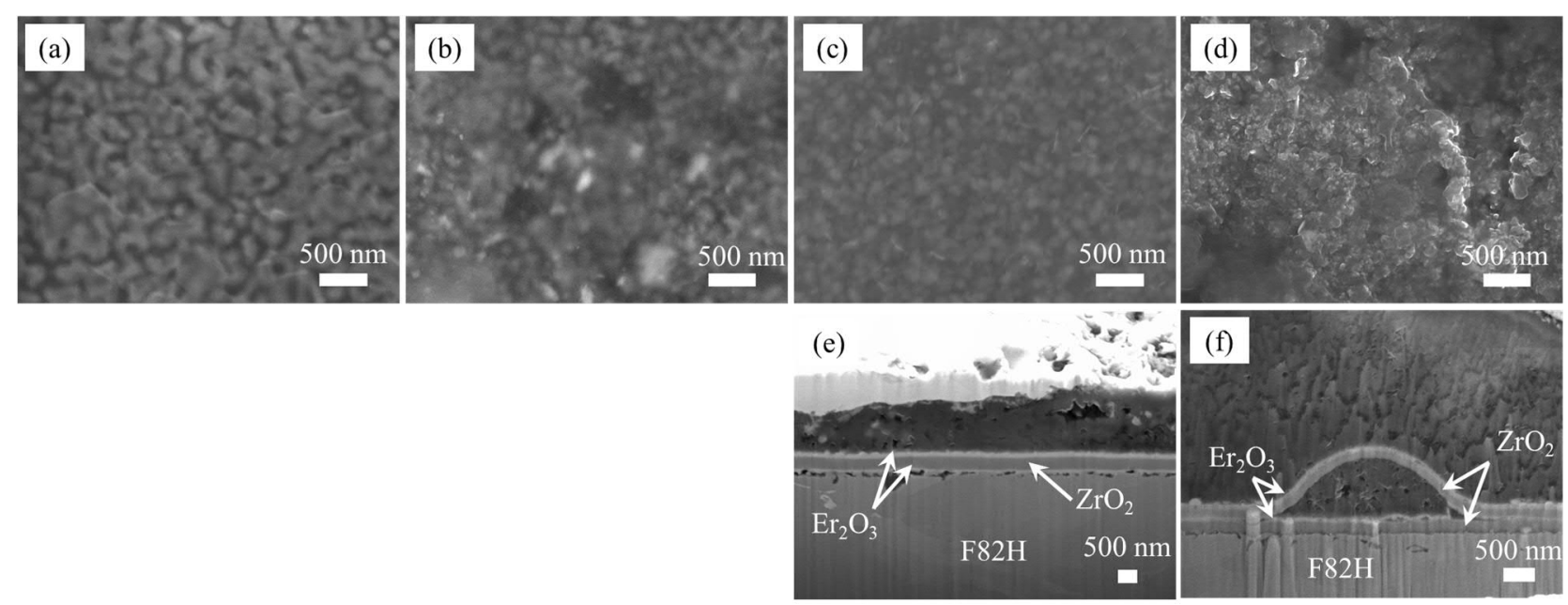

Fig. 4. Surface and cross-sectional SEM images of coating samples after Li-Pb exposure test for $500 \mathrm{~h}$ at $600{ }^{\circ} \mathrm{C}$ :

(a) Sample A, (b) Sample B, (c) (e) Sample C, and (d) (f) Sample D.

Fig. 3 shows surface and cross-sectional SEM images of the samples after $\mathrm{Li}-\mathrm{Pb}$ exposure for $500 \mathrm{~h}$ at $500{ }^{\circ} \mathrm{C}$. Surfaces of Samples A-C that the outermost layer is $\mathrm{ZrO}_{2}$ were smooth after exposure for $500 \mathrm{~h}$ at $500^{\circ} \mathrm{C}$, which indicates negligibly little corrosion. On the other hand, Fig. 3(d) indicates the surface of the outermost $\mathrm{Er}_{2} \mathrm{O}_{3}$ layer became rough, suggesting that the corrosion occurred for Sample D. In addition, Fig. 3(e) shows a huge bank caused by an interlamellar peeling in Sample B. However, it was observed only in portion. The interlamellar peeling between the second $\mathrm{Er}_{2} \mathrm{O}_{3}$ layer and the third $\mathrm{ZrO}_{2}$ layer was observed in Sample C, as shown in Fig. 3(f). Cracks and peelings were also confirmed around the area which the interlamellar peeling generated.

After the exposure test for $500 \mathrm{~h}$ at $550{ }^{\circ} \mathrm{C}$, no degradation was observed in Samples A-C, but peelings were observed in Sample D.

Surface and cross-sectional SEM images of the samples after $\mathrm{Li}-\mathrm{Pb}$ exposure for $500 \mathrm{~h}$ at $600{ }^{\circ} \mathrm{C}$ are shown in Fig. 4. After exposure, the outermost $\mathrm{ZrO}_{2}$ layers of Samples A-C seemed to be corroded because the surfaces became rough, as shown in Fig. 4(a)-(c). In Sample D, the surface of the outermost $\mathrm{Er}_{2} \mathrm{O}_{3}$ layer became rougher than the samples after the $\mathrm{Li}-\mathrm{Pb}$ exposure at $500{ }^{\circ} \mathrm{C}$ and $550{ }^{\circ} \mathrm{C}$, as shown in Fig. 4(d), indicating that the corrosion depends on the test temperature. Peelings of the outermost $\mathrm{ZrO}_{2}$ layer were confirmed in Sample C, and interlamellar peelings between the second $\mathrm{Er}_{2} \mathrm{O}_{3}$ layer and the third $\mathrm{ZrO}_{2}$ layer were confirmed in Sample D, as shown in Fig. 4(e) and (f).

After the test for $1000 \mathrm{~h}$ at $600{ }^{\circ} \mathrm{C}$, corrosion further progressed in all the samples, compared with the tests for 500 h. In particular, in Sample D, the outermost $\mathrm{Er}_{2} \mathrm{O}_{3}$ layer was mostly lost by corrosion, and many cracks were observed in the third $\mathrm{ZrO}_{2}$ layer. In Sample C, cracks were also confirmed on the outermost $\mathrm{ZrO}_{2}$ layer. Surface SEM images of the samples after $\mathrm{Li}-\mathrm{Pb}$ exposure for $2000 \mathrm{~h}$ at $600{ }^{\circ} \mathrm{C}$ are shown in Fig. 5. Surface corrosion were confirmed in Samples A-C, while no degradation such as cracks and peelings was observed. Sample D lost one or two layers from the surface, and many cracks were observed in the remaining coatings. Moreover, the substrate was partly exposed on the surface. 

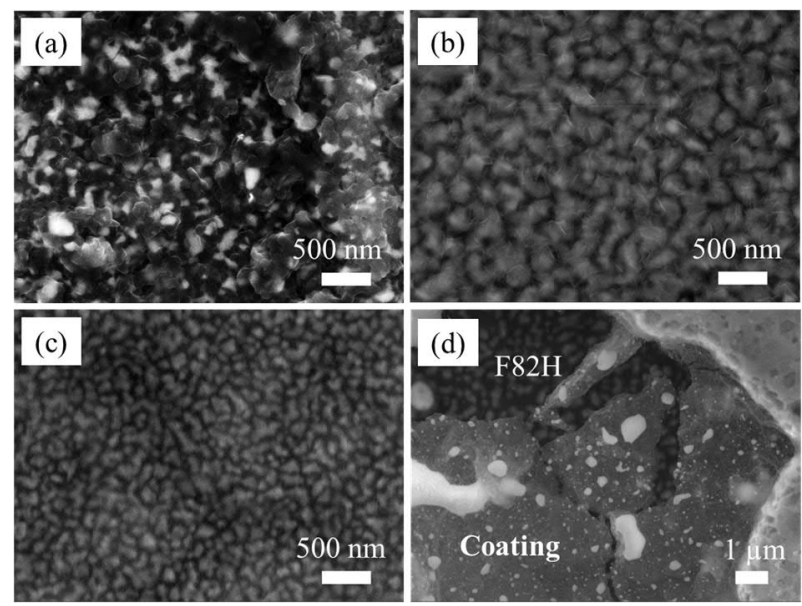

Fig. 5. Surface SEM images of coating samples after $\mathrm{Li}-\mathrm{Pb}$ exposure test for $2000 \mathrm{~h}$ at $600^{\circ} \mathrm{C}$ : (a) Sample A,

(b) Sample B, (c) Sample C, and (d) Sample D

\section{Discussion}

\section{1 Corrosion}

We found that the corrosion behavior depended on coating material of the outermost layer. The corrosion of the outermost $\mathrm{Er}_{2} \mathrm{O}_{3}$ layer was confirmed by surface roughness after the $\mathrm{Li}-\mathrm{Pb}$ exposure at $500-600{ }^{\circ} \mathrm{C}$. A corrosion process would be that $\mathrm{Er}_{2} \mathrm{O}_{3}$ was dissolved by a reaction with lithium and dissolved oxygen as proposed in the references $[5,10]$ :

$$
\mathrm{Er}_{2} \mathrm{O}_{3}+2 \mathrm{Li}+\mathrm{O}[\mathrm{Li}] \rightarrow 2 \mathrm{LiErO}_{2}
$$

This reaction might occur at lower temperature than 500 ${ }^{\circ} \mathrm{C}$ from the result of Fig. 3(d) and be accelerated at higher temperatures. From the results of the exposure test for $1000 \mathrm{~h}$ and $2000 \mathrm{~h}$ at $600{ }^{\circ} \mathrm{C}$, the outermost $\mathrm{Er}_{2} \mathrm{O}_{3}$ layer was almost removed and it seemed to lose the function as a coating. On the other hand, the surface of the outermost $\mathrm{ZrO}_{2}$ layer became rough only after the exposure tests at $600^{\circ} \mathrm{C}$. Thus, $\mathrm{ZrO}_{2}$ coatings would be corroded at higher temperature $\left(\geq 600^{\circ} \mathrm{C}\right)$ via the following reaction:

$$
\mathrm{ZrO}_{2}+2 \mathrm{Li}+\mathrm{O}[\mathrm{Li}] \rightarrow \mathrm{Li}_{2} \mathrm{ZrO}_{3}
$$

The surfaces of all the samples after exposure for $2000 \mathrm{~h}$ were rougher than that for 500 and $1000 \mathrm{~h}$. It was assumed that this reaction progressed with time.

The corrosion of the outermost $\mathrm{Er}_{2} \mathrm{O}_{3}$ layer was observed from $500^{\circ} \mathrm{C}$, whereas that of $\mathrm{ZrO}_{2}$ layer was observed only at $600^{\circ} \mathrm{C}$. From these results, $\mathrm{ZrO}_{2}$ is more suitable as an outermost layer than $\mathrm{Er}_{2} \mathrm{O}_{3}$.

\subsection{Crack and peeling formation}

The formation of cracks and peelings are mainly caused by changes in temperature during coating fabrication and/or the $\mathrm{Li}-\mathrm{Pb}$ exposure tests because of a difference in the coefficient of thermal expansion (CTE) of the ceramic coatings. One of the causes of peeling is the invasion of $\mathrm{Li}-\mathrm{Pb}$ and the carbon-based corrosion product through cracks and pores in the outermost layer.
In principle, $\mathrm{Li}-\mathrm{Pb}$ corrosion progresses at high temperatures, but the stress on the coating due to the difference in CTE depends on the fabrication temperature. Since the coatings were heat-treated at $700{ }^{\circ} \mathrm{C}$, the compressive stress arose at the temperature lower than $700{ }^{\circ} \mathrm{C}$, and then the larger stress arose in the $\mathrm{Li}-\mathrm{Pb}$ exposure tests at $500{ }^{\circ} \mathrm{C}$ than $550{ }^{\circ} \mathrm{C}$, suggesting a cause of the interlamellar peeling of Samples B and C.

In Samples $\mathrm{C}$ and $\mathrm{D}$, the coating degradation such as cracking and peeling was more serious than in Samples A and $\mathrm{B}$ based on the trends in all the test results. A common point between Samples A and B is that the outermost $\mathrm{ZrO}_{2}$ layer was fabricated on the $\mathrm{ZrO}_{2}$ layer, and these samples had two and three layers of $\mathrm{ZrO}_{2}$ on the $\mathrm{Er}_{2} \mathrm{O}_{3}$ layer. In contrast, Sample C consisted of one outermost $\mathrm{ZrO}_{2}$ layer on an inner $\mathrm{Er}_{2} \mathrm{O}_{3}$ layer, and Sample D consisted of one outermost $\mathrm{Er}_{2} \mathrm{O}_{3}$ layer on an inner $\mathrm{ZrO}_{2}$ layer. When the coating repeated the fabrication process for four times with $\mathrm{Er}_{2} \mathrm{O}_{3}$ and $\mathrm{ZrO}_{2}$ alternately, a stress caused by CTE mismatch would be so large that cracks easily generated during temperature change. On the other hand, the stress might be dispersed in the coating repeated the fabrication process with the same material, resulting in the prevention of crack formation. However, Sample B showed an interlamellar peeling at a single place after exposure for $500 \mathrm{~h}$ at $500{ }^{\circ} \mathrm{C}$. From these results, we consider that increasing the number of coating fabrication process is effective to mitigate the degradation of the coating, but the degradation might not be completely prevented.

Crack formation might have been suppressed by stress distribution due to increasing the number of coating fabrication process; therefore, less cracks might form in the outermost layer fabricated on the same material layer. Fig. 6 shows the possible mechanisms of the formation of crack and peeling. The sample that has less cracks in the outermost layer hardly causes peeling. Samples A and B indicated less cracks and peelings for these reasons. In contrast, the coating of Sample D formed cracks after the $\mathrm{Li}-\mathrm{Pb}$ exposure test for $500 \mathrm{~h}$ at $500{ }^{\circ} \mathrm{C}$, and peelings were observed after the test at $550{ }^{\circ} \mathrm{C}$. We consider that only cracking might occur due to a CTE mismatch at $500{ }^{\circ} \mathrm{C}$, and the invasion of $\mathrm{Li}-\mathrm{Pb}$ from the cracks cause peelings at $550^{\circ} \mathrm{C}$.
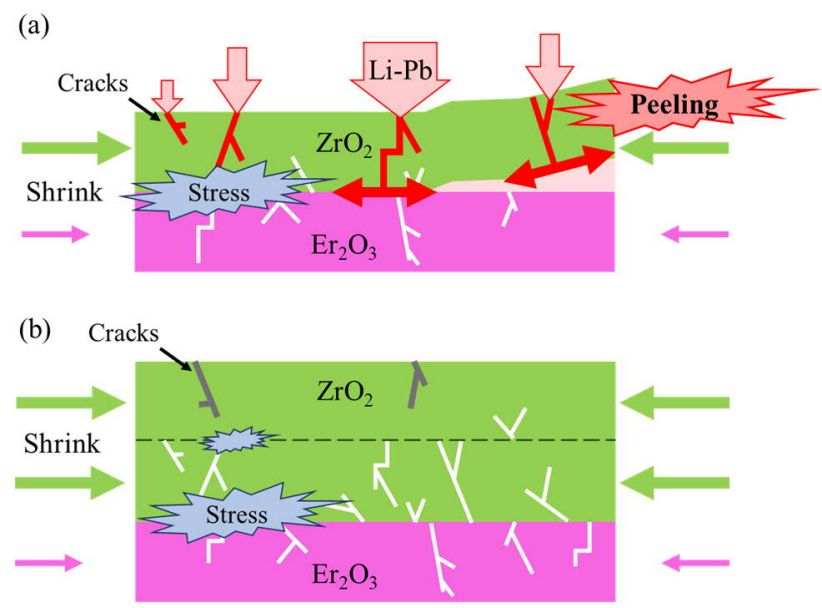
Fig. 6. Conceptual diagram of coating degradation in (a) $\mathrm{ZrO}_{2}$ outermost layer on $\mathrm{Er}_{2} \mathrm{O}_{3}$ layer, (b) $\mathrm{ZrO}_{2}$ outermost layer on $\mathrm{Er}_{2} \mathrm{O}_{3}-\mathrm{ZrO}_{2}$ layer.

The interlamellar peelings in Sample $\mathrm{D}$ after Li-Pb exposure for $500 \mathrm{~h}$ at $600{ }^{\circ} \mathrm{C}$ were observed the interface between the second $\mathrm{Er}_{2} \mathrm{O}_{3}$ layer and the third $\mathrm{ZrO}_{2}$ layer. In Sample $\mathrm{C}$, peelings of the outermost $\mathrm{ZrO}_{2}$ layer on the $\mathrm{Er}_{2} \mathrm{O}_{3}$ layer as well as the interlamellar peeling were observed after $\mathrm{Li}-\mathrm{Pb}$ exposure for $500 \mathrm{~h}$ at $600{ }^{\circ} \mathrm{C}$. From these results, the $(\mathrm{F} 82 \mathrm{H}-) \mathrm{Er}_{2} \mathrm{O}_{3}-\mathrm{ZrO}_{2}$ interface would have lower integration than the $\mathrm{ZrO}_{2}-\mathrm{Er}_{2} \mathrm{O}_{3}$ interface. One clear difference between the $\mathrm{Er}_{2} \mathrm{O}_{3}$ and $\mathrm{ZrO}_{2}$ coatings is the coating thickness. In a report of the effect of the coating thickness on the stress and adhesion of the coatings with a thickness of $\sim 200 \mathrm{~nm}$, the coating thickness affects compressive stress and adhesive strength [10]. The thicknesses of the $\mathrm{Er}_{2} \mathrm{O}_{3}$ and $\mathrm{ZrO}_{2}$ layers were approximately 50 and $150 \mathrm{~nm}$, respectively. Since the $\mathrm{ZrO}_{2}$ layer has a thickness three times as large as the $\mathrm{Er}_{2} \mathrm{O}_{3}$ layer, the interlamellar peeling might occur because of the difference in the adhesion of the layers. In addition, the fabrication process should be also considered to evaluate integrity of the multi-layer coatings in the further investigation.

\section{Conclusion}

Multi-layer coatings with various layer structures using $\mathrm{Er}_{2} \mathrm{O}_{3}$ and $\mathrm{ZrO}_{2}$ were fabricated by MOD and then exposed to $\mathrm{Li}-\mathrm{Pb}$ under static conditions. The observation after the $\mathrm{Li}-\mathrm{Pb}$ exposure tests showed that the corrosion behavior varied with the test temperature and time as well as the layer structure. Corrosion proceeded in the outermost $\mathrm{Er}_{2} \mathrm{O}_{3}$ layer after all the exposure tests, and the most layer was lost after the exposure test for $1000 \mathrm{~h}$ at $600{ }^{\circ} \mathrm{C}$. On the other hand, corrosion progressed in the outermost $\mathrm{ZrO}_{2}$ layer only after the exposure tests at 600 ${ }^{\circ} \mathrm{C}$. $\mathrm{ZrO}_{2}$ would be more suitable as the outermost layer of multi-layer coatings than $\mathrm{Er}_{2} \mathrm{O}_{3}$. After the exposure test for $1000 \mathrm{~h}$ at $600{ }^{\circ} \mathrm{C}$, many cracks and peelings were observed in the coatings with three coating interfaces. In the coatings with the outermost $\mathrm{ZrO}_{2}$ layer and one coating interface, less degradation was confirmed. The optimization of layer combination is important to reduce the degradation of multi-layer coatings. In addition, the thickness of the coating might be related to an integration between the coatings.

\section{Acknowledgments}

This work was supported by JSPS KAKENHI Grant Number 19H01873, the general collaboration research with National Institute for Fusion Science (NIFS18KEMF119), and Research Foundation for the Electrotechnology of Chubu Receipt Number E-01115.

\section{References}

[1] Ch. Linsmeier et al., Development of advanced high heat flux and plasma-facing materials, Nucl. Fusion 57 (092007) (2017) 60.

[2] T. Chikada et al., Surface behavior in deuterium permeation through erbium oxide coatings, Nucl. Fusion 51 (063023) (2011) 5 .

[3] T. Chikada et al., Microstructure control and deuterium permeability of erbium oxide coating on ferritic/martensitic steels by metal-organic decomposition, Fusion Eng. Des. 85 (2010) 1537-1541.

[4] T. Chikada et al., Crystallization and deuterium permeation behaviors of yttrium oxide coating prepared by metal organic decomposition, Nucl. Mater. Energy 9 (2016) 529534.

[5] M. Matsunaga et al., Lithium-lead corrosion behavior of erbium oxide, yttrium oxide and zirconium oxide coatings fabricated by metal organic decomposition, J. Nucl. Mater. 511 (2018) 534-543.

[6] J. Mochizuki et al., Preparation and characterization of $\mathrm{Er}_{2} \mathrm{O}_{3}-\mathrm{ZrO}_{2}$ multi-layer coating for tritium permeation barrier by metal organic decomposition, Fusion Eng. Des. 136 (2018) 219-222.

[7] T. Tanaka et al., Control of substrate oxidation in MOD ceramic coating on low-activation ferritic steel with reduced-pressure atmosphere, J. Nucl. Mater. 455 (2014) 630-634.

[8] T. Chikada et al., Fabrication technology development and characterization of tritium permeation barriers by a liquid phase method, Fusion Eng. Des. 136 (2018) 215-218.

[9] M. Nagura et al., $\mathrm{LiErO}_{2}$ formation on $\mathrm{Er}_{2} \mathrm{O}_{3}$ in static and natural convention lithium, Fusion Eng. Des. 84 (2009) 1384-1387.

[10] D. Sheeja et al., Effect of film thickness on the stress and adhesion of diamond-like carbon coatings, Diamond Related Mater. 11 (2002) 1643-1647. 